\title{
Aspectos físico-químicos e microbiológicos de grãos de soja tratados com ácidos orgânicos e seus sais
}

\author{
Physical-chemical and microbiological aspects of soybean grain treated with organic acid \\ and their salts
}

\author{
Andréia Letícia Engelmann ${ }^{\mathrm{I}}$ Fernando Reimann Skonieski ${ }^{\mathrm{II}}$ Alexandre Mossate Gabbi ${ }^{\mathrm{II}}$ \\ Ivair Piccinin $^{\mathrm{IV}}$ Jorge André Fantoni Bencke $^{\mathrm{III}}$ Julio Viégas ${ }^{\mathrm{V}}$
}

\section{RESUMO}

Este trabalho teve por objetivo avaliar os parâmetros microbiológicos e físico-químicos do grão de soja (Glycine $\max$ L.) desativado, tratado com três diferentes dosagens (2, 4 e $\left.6 \mathrm{~L} \mathrm{t}^{-1}\right)$ de uma mistura de ácidos orgânicos e seus sais (AOS), com a função de aditivo antifúngico. $O$ ensaio teve uma duração de 90 dias, em que foram feitas a contagem de bolores e leveduras (UFC $\mathrm{g}^{-1}$ ), e a identificação dos gêneros fúngicos, da umidade (U), da atividade de água (AA), do índice de peróxido (IP) e do índice de acidez (IA). As análises foram realizadas em triplicata, em intervalos de 15 dias entre cada análise, até o 60 dia de avaliação e depois no 90 dia do experimento. Verificou-se aumento na UFC $g^{-1}$ nas doses de 2 e $4 L t^{-1}$, bem como mudança nos gêneros fúngicos encontradas nestes tratamentos a cada avaliação, diferentemente da baixa UFC $g^{-1}$ e da identificação de gêneros na dose de $6 L t^{-1}$. Os valores de $U$ e AA mantiveram-se acima dos padrões recomendados de $14 \%$ e 0,70 , respectivamente em todos os tratamentos e avaliações. O IP aumentou significativamente a partir do $45^{\circ}$ dia de avaliação no controle e a partir do $60^{\circ}$ dia nos demais tratamentos. O IA não variou significativamente durante o período de avaliação. Conclui-se que a dosagem de $6 L t^{1}$ foi eficiente na proteção antifúngica desta matéria-prima.

Palavras-chave: contaminação fúngica, conservação de grãos, antifúngicos.

\section{ABSTRACT}

This research had the objective to evaluate microbiological and physical-chemical parameters of deactivated soybean grain (Glycine max L.) treated with three different dosages (2, 4 and $6 L t^{-1}$ ) of organic acids and their salts mixture (AOS), as an antifungical additive. The assay had a duration of 90 days, where executed fungi count (UFC $g^{-1}$ ), fungi specie identification, humidity $(U)$, activity of water $(A A)$, peroxide value (IP) and acidity value (IA). The analyses were carried out in triplicate, in intervals of 15 days among analysis, until $60^{\text {th }}$ day of evaluation and, at the $90^{\text {th }}$ day of evaluation. There were increases in the UFC $g^{-1}$ in dosages of 2 and $4 L t^{1}$, as well a change in fungi species found in these treatment at each evaluation, distinguished of low UFC $g^{-1}$ and fungi species in dosage of $6 \mathrm{~L} \mathrm{t}^{-1}$. The values of $U$ and $A A$ were above of recommended patterns of $14 \%$ and 0.70 , respectively for all treatments and evaluations. The IP increased significative from $45^{\text {th }}$ day of evaluation in control and from $60^{\text {th }}$ day in other treatments. The IA had no significative variation during the period of evaluation. The dosage of $6 \mathrm{~L} \mathrm{t}^{-1}$ was efficient in the antifungical protection of this raw material.

Key words: fungi contamination, grain preservation, antifungical.

\section{INTRODUÇÃO}

A soja (Glycine max L.) é uma das matériasprimas mais utilizadas na produção animal, como fonte de proteína, sendo fornecida em diferentes formas físicas para alimentação de monogástricos e ruminantes, geralmente após o tratamento térmico do grão inteiro, a fim de desnaturar a enzima urease (TEIXEIRA \& TEIXEIRA, 2001).

IPrograma de Pós-graduação em Engenharia de Alimentos, Universidade Federal de Santa Catarina (UFSC), Florianópolis, SC, Brasil.

IIPrograma de Pós-graduação em Zootecnia, Universidade Federal de Santa Maria (UFSM), Santa Maria, RS, Brasil.

IIIDepartamento de Pesquisa e Desenvolvimento, Eurotec Nutriton do Brasil, Palhoça, SC, Brasil. E-mail: mgabbi@yahoo.com.br. *Endereço para correspondência. Estrada Geral de Linha Base, Vila Cattani, 97195-000, Silveira Martins, RS, Brasil.

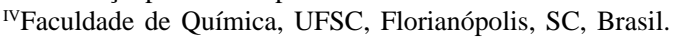

vepartamento de Zootecnia, UFSM, Santa Maria, RS, Brasil. 
A utilização do grão inteiro propicia que os níveis de gordura sejam praticamente integrais nesta matéria-prima (PEIXOTO \& MAIER, 1993), sendo uma fonte disponível de nutrientes para que os microrganismos possam se desenvolver em ambiente de armazenagem (PONT et al., 2001). Diversos autores (SANTIN, 2001; GOCK et al., 2003; HERMANNS et al., 2006) descreveram que matérias-primas, tais como milho, soja, trigo e arroz, quando armazenados, sem sofrer nenhum processo que altere sua forma física ou sem tratamento químico para preservação, perdem rapidamente suas qualidades nutricionais devido à contaminação por microrganismos.

O uso de ácidos orgânicos e seus sais são amplamente difundidos como forma de proteger matérias-primas e rações destinadas à alimentação animal contra a contaminação fúngica e bacteriana (LIN \& CHEN, 1995; GOULD, 1996; ALBUQUERQUE et al., 1998, GUYNOT et al., 2005). O uso da mistura de ácidos orgânicos e seus sais possibilitam baixos níveis de inclusões com médio prazo de efetividade na proteção contra bolores e leveduras (SAVARD et al., 2002). Entre os ácidos e sais comumente utilizados estão o ácido propiônico, o ácido acético, o ácido lático, o propionato de cálcio, acetato de sódio e sorbato de potássio (SUHR \& NIELSEN, 2004; NAZER et al., 2005).

Este trabalho teve por objetivo avaliar parâmetros microbiológicos e físico-químicos do grão de soja desativado destinado à alimentação animal, tratado com mistura de ácidos orgânicos e seus sais.

\section{MATERIAL E MÉTODOS}

Este trabalho foi conduzido em conjunto com o Laboratório de Análises Físico-Químicas da Eurotec Nutrition do Brasil (Palhoça, SC), o Laboratório de Microbiologia do Departamento de Tecnologia e Ciência dos Alimentos e o Laboratório de Pesquisas Micológicas, ambos da Universidade Federal de Santa Maria (Santa Maria, RS), durante o período de novembro de 2005 a fevereiro de 2006.

As amostras de grão de soja desativado foram obtidas no município de Palotina (PR). Foi coletada uma quantidade homogênea de $20 \mathrm{~kg}$ e sorteada ao acaso nos quatro tratamentos estipulados para o experimento: controle, sem adição de mistura de ácidos orgânicos e seus sais (AOS), e a adição de dois, quatro e seis litros da mistura de AOS por tonelada de grão de soja desativado. As amostras sorteadas, para os tratamentos com adição de ácidos orgânicos e seus sais, foram pulverizadas com a mistura de AOS por meio de bomba dosadora e bico de pulverização em spray. Logo após, as amostras foram acondicionadas em embalagens, comumente utilizadas para acondicionamento desta matéria-prima, e armazenadas em local que reproduzisse as condições verificadas em galpões de armazenagem, com temperatura média $20^{\circ} \mathrm{C}$ e umidade relativa do ar ambiente em torno de 70\%, conforme CASINI (2003). A composição básica do AOS utilizado foi ácido propiônico (20\%), ácido acético (15\%), propionato de cálcio (5\%), acetato de sódio (5\%) e sorbato de potássio (5\%). Como veículo, foi utilizado monoetilenoglicol na quantidade de $50 \%$ na formulação proposta para o teste.

As variáveis avaliadas foram contagens de bolores e leveduras, em unidades formadoras de colônia por grama de amostra, e identificação dos gêneros fúngicos, pelo método de diluições seriadas cultivadas em meio de cultivo dicloran rosa de bengala cloranfenicol (DRBC) (TANIWAKI, 1996). Além disso foi avaliada a umidade, em percentual, a partir da secagem das amostras em estufa de ar forçado a $105^{\circ} \mathrm{C}$ (AOAC, 1995) a atividade de água, em unidades, por aplicação da metodologia do ponto de orvalho (AOAC, 1995) o índice de peróxido por extração de gordura a frio, em miliequivalente de peróxido por quilograma de amostra, conforme metodologia descrita por BLIGH \& DYER (1959) e o índice de acidez, em miligramas de hidróxido de sódio por grama de amostra, por neutralização e titulação com hidróxido de sódio 0,1N (ANFAL, 1998).

As análises foram realizadas 12 horas após a aplicação da mistura de AOS, sendo considerado este o dia zero, e, nos dias 15, 30, 45, 60 e 90, depois da aplicação do AOS sobre o grão de soja desativado. Em todas as amostras antes de serem submetidas à análise, era coletada uma alíquota de aproximadamente $500 \mathrm{~g}$ de cada tratamento e moída em moinho de martelo e então separada para as distintas análises.

O experimento foi um fatorial $4 \times 6$, com quatro tratamentos, seis períodos de avaliação e três repetições. Os dados obtidos foram submetidos à Análise de Regressão em nível de 5\% de significância. Foi utilizado o pacote estatístico SAS for Windows (SAS INSTITUTE, 1999) para avaliação estatística dos dados.

\section{RESULTADOS E DISCUSSÃO}

O perfil de desenvolvimento fúngico, nos diferentes tratamentos, pode ser observado na figura 1. Percebe-se que o os grãos tratados com $6 \mathrm{~L} \mathrm{t}^{-1} \mathrm{da}$ mistura de AOS apresentaram a maior constância nos resultados referente a este parâmetro e nos períodos de avaliações foi a dosagem com maior eficiência contra o desenvolvimento da flora fúngica. Os grãos do 


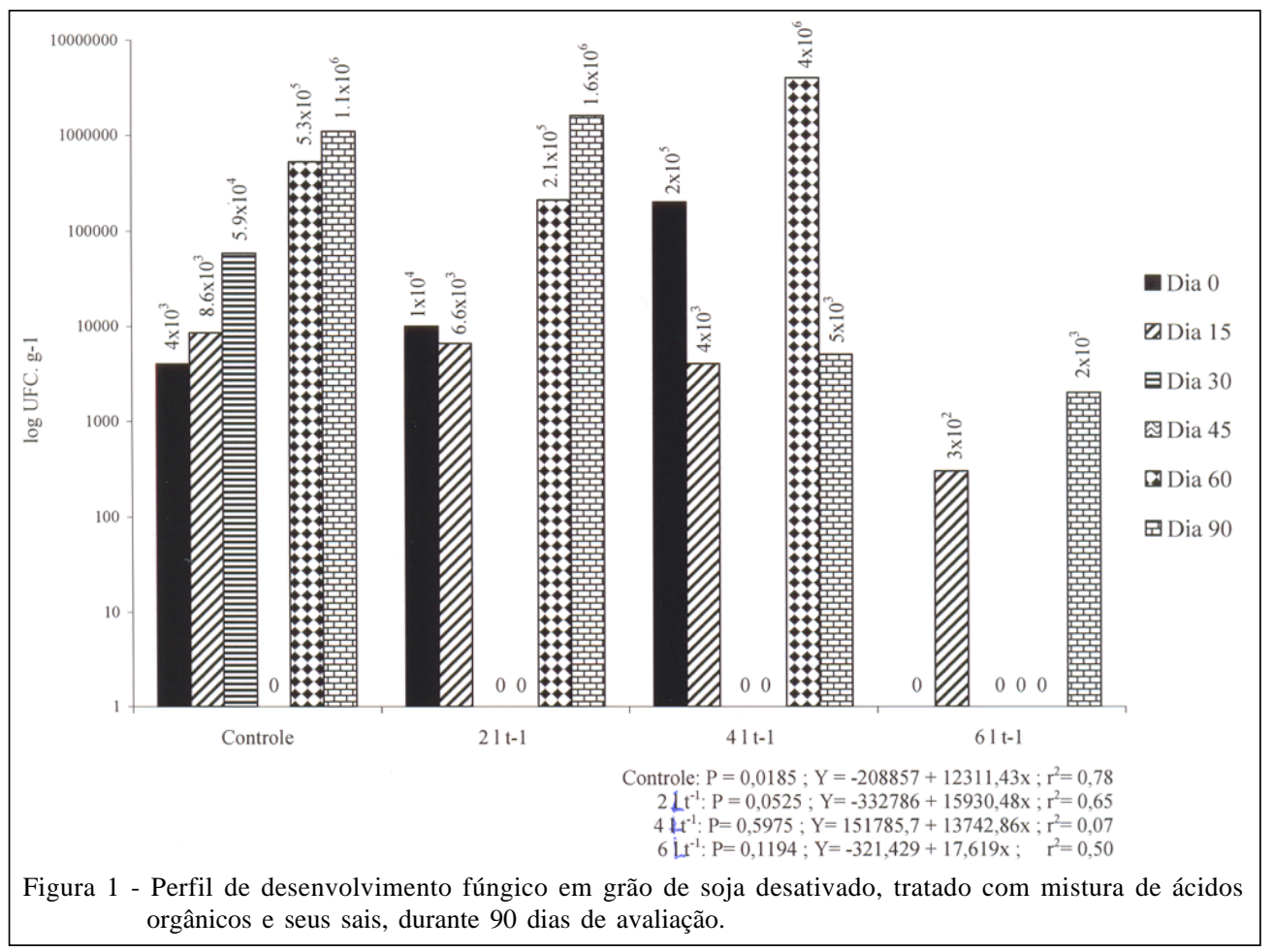

tratamento controle apresentaram, em todos os períodos de avaliação, contagem de bolores e leveduras, com exceção no dia 45 de avaliação. Os grãos dos tratamentos com adição de 2 e $4 \mathrm{l} \mathrm{t}^{-1}$ apresentaram alta contagem fúngica no início do experimento, porém o número de colônias foi declinando até cessar o desenvolvimento nos dias 30 e 45 de avaliação, apresentando desenvolvimento positivo e crescente nos períodos seguintes, possivelmente pela perda de eficiência do produto.

Esses resultados estão de acordo com os dados observados por SUHR \& NIELSEN (2004), os quais verificaram que a mistura de ácidos orgânicos para proteção de diferentes matérias-primas destinadas à alimentação animal na dosagem de $3 \mathrm{~L} \mathrm{t} \mathrm{t}^{-1}$ é eficiente durante 30 dias. RAHNEMA \& NEAL (1994) ao utilizarem diferentes ácidos orgânicos, verificaram que houve inibição inicial no desenvolvimento fúngico, porém, no correr do tempo, essa aplicação de ácidos perdeu a função de proteger contra a contaminação e o desenvolvimento de bolores e leveduras em matériasprimas e rações destinadas à alimentação animal.

Neste trabalho, os gêneros encontrados nos diferentes tratamentos estão descritos na tabela 1 . Se observado, os gêneros Aspergillus sp. e leveduras foram os mais encontrados. Segundo SANTIN (2001) e HOELTZ (2005), o gênero Aspergillus sp. é comumente encontrado em grãos recém-colhidos. No presente estudo, os tratamentos com 2 e $4 \mathrm{~L} \mathrm{t}^{-1}$ não foram eficientes para inibir o aparecimento destes gêneros. Os fungos leveduriformes são considerados oportunistas na contaminação de matérias-primas e rações destinadas à alimentação animal (SAVARD et al., 2002), mas quando a dosagem foi eficiente, como no tratamento com $6 \mathrm{~L} \mathrm{t}^{-1}$ da mistura de AOS, não houve desenvolvimento destes contaminantes.

A análise de regressão para umidade e atividade de água nos diferentes tratamentos encontrase descritas nas figuras 2 e 3, respectivamente. Até o $30^{\circ}$ dia de avaliação, os níveis de umidade permaneceram dentro dos parâmetros recomendados para matérias-primas e rações (ANFAL, 1998). Porém, a partir deste período, o nível de umidade excedeu $14 \%$, gerando um ambiente favorável ao desenvolvimento de fungos e leveduras (DIEKMAN \& GREEN, 1992; GOULD, 1996). Este fato pode ter colaborado para a elevada contagem de bolores e leveduras observadas nos tratamentos controle e com 2 e $4 \mathrm{~L} \mathrm{t}^{-1}$ da mistura de AOS. A maior concentração da mistura de AOS, aplicada no tratamento com $6 \mathrm{~L} \mathrm{t}^{-1}$, foi eficiente em um nível de umidade propício ao desenvolvimento desses microrganismos.

A atividade de água verificada nos grãos de soja utilizados no experimento esteve sempre acima do nível considerado seguro, de 0,70 (DITCHFIELD, 2000) desde o início das avaliações em todos os tratamentos. 
Tabela 1 - Representantes fúngicos encontrados em grão de soja desativado, tratado com mistura de ácidos orgânicos e seus sais, durante 90 dias de avaliação.

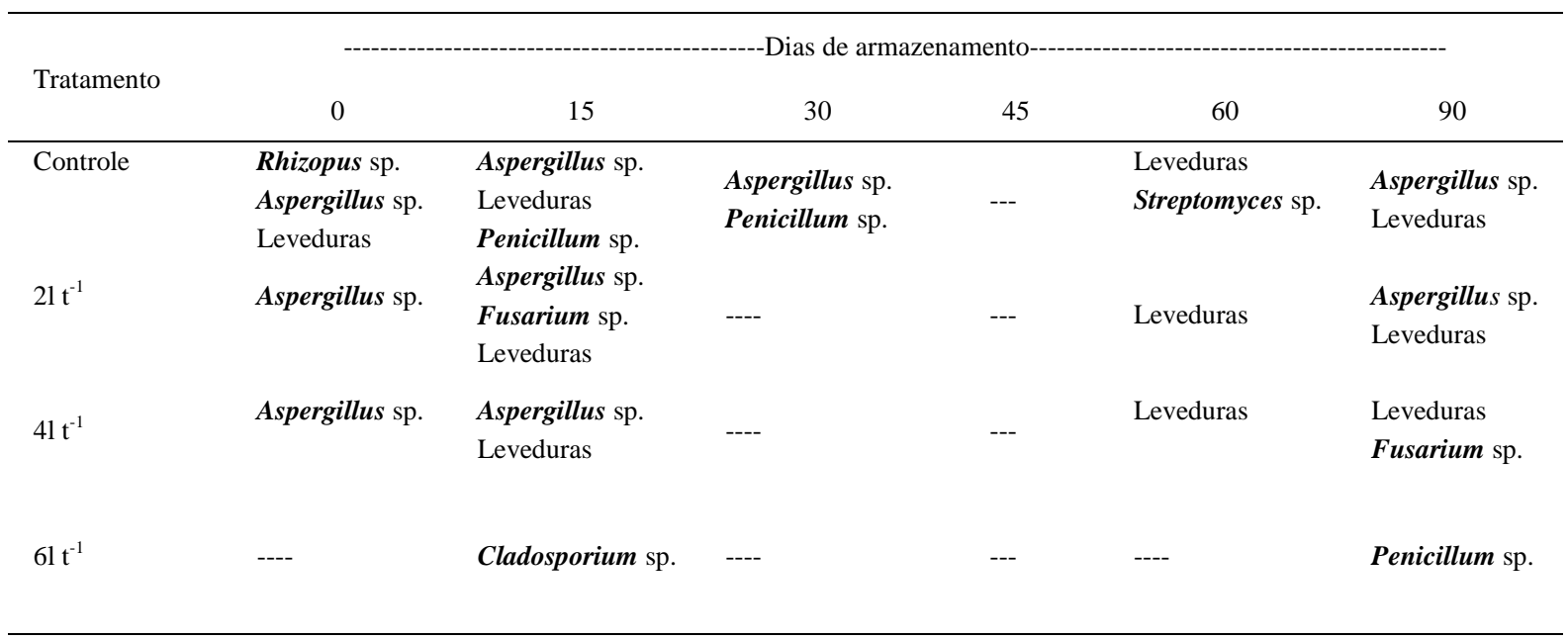

A incorporação de 2 , 4 e $6 \mathrm{~L} \mathrm{t}^{-1}$ não foi eficiente para controlar o nível de atividade de água encontrado nas amostras. Todavia, no tratamento com $6 \mathrm{~L} \mathrm{t}^{-1}$, mesmo com um valor de atividade de água favorável ao desenvolvimento de bolores e leveduras, não foram observadas altas contagens destes fungos.

A análise de regressão para índice de peróxido está descrita na figura 4. Observa-se um crescimento desse índice a partir do dia 45 de avaliação. Este pode estar relacionado a dois fatores: o primeiro pela decomposição e consumo dos ácidos graxos presentes por parte dos bolores e leveduras contaminantes do grão de soja desativado (PONT et al., 2001) e o segundo pelo não fornecimento de proteção antioxidante a esta matéria-prima (DECKER et al., 2005). O primeiro fator descrito está intimamente relacionado

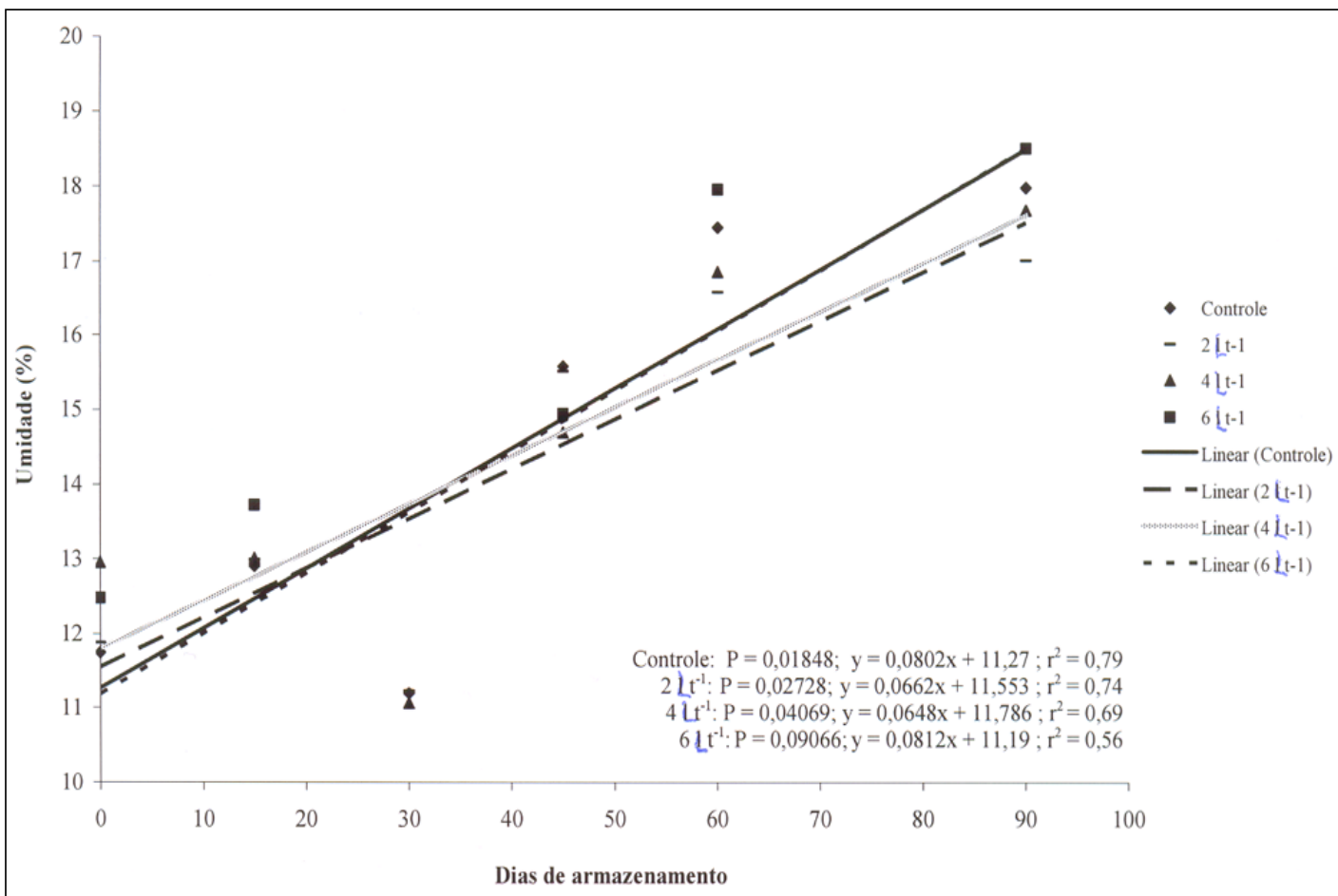

Figura 2 - Análise de regressão do parâmetro umidade em grão de soja desativado, tratado com mistura de ácidos orgânicos e seus sais, durante 90 dias de avaliação. 


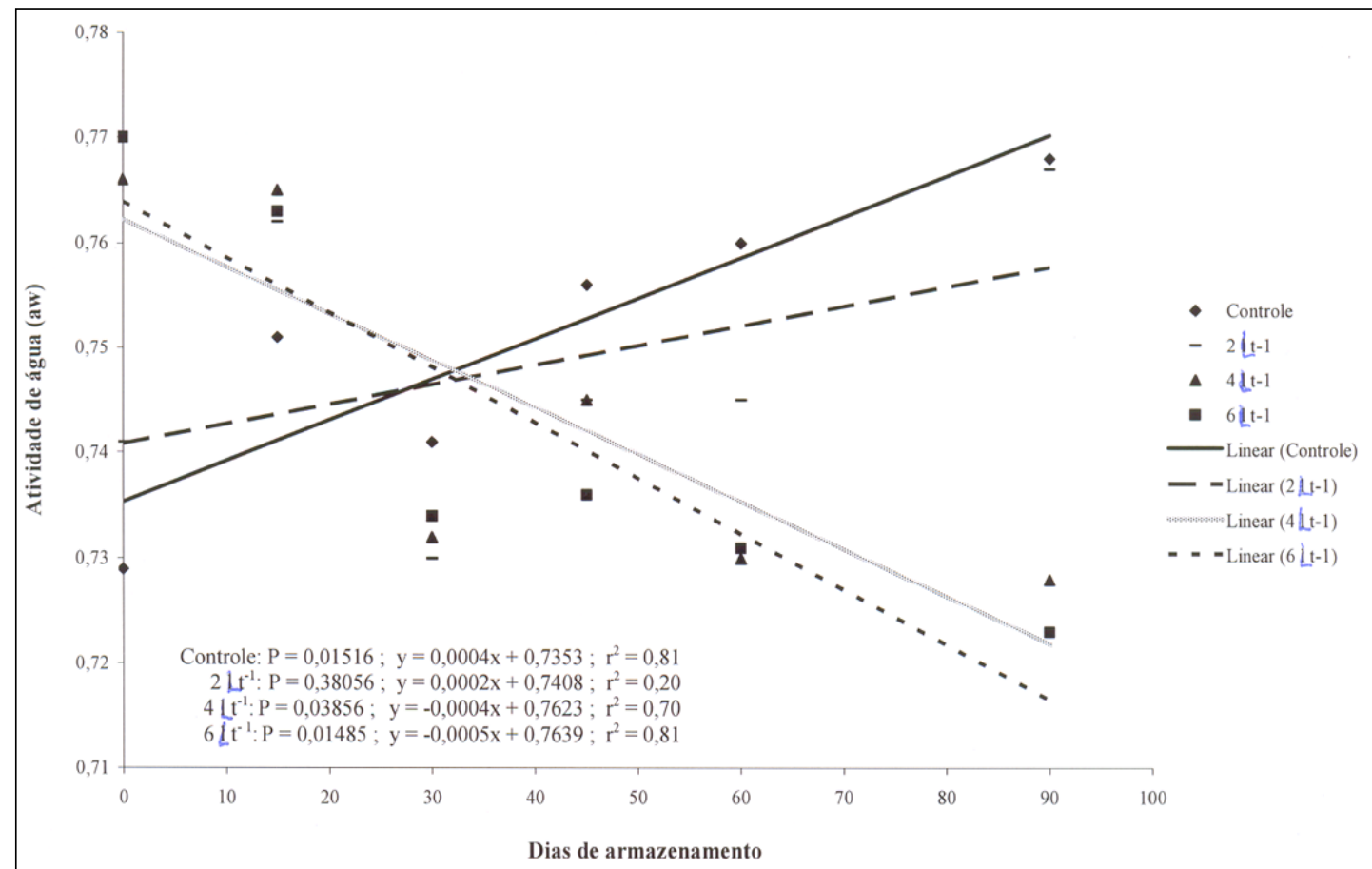

Figura 3 - Análise de regressão do parâmetro atividade de água em grão de soja desativado, tratado com mistura de ácidos orgânicos e seus sais, durante 90 dias de avaliação.

aos dados observados nos tratamentos controle, 2 e $4 \mathrm{~L} \mathrm{t}^{-1}$ da mistura de AOS. A não-proteção antioxidante também possui relação com os níveis de peróxido encontrados, porém parece mais relacionado ao tratamento contendo $6 \mathrm{~L} \mathrm{t}^{-1}$ da mistura deAOS.

Não houve diferenças significativas entre os índices de acidez em todos os tratamentos, porém

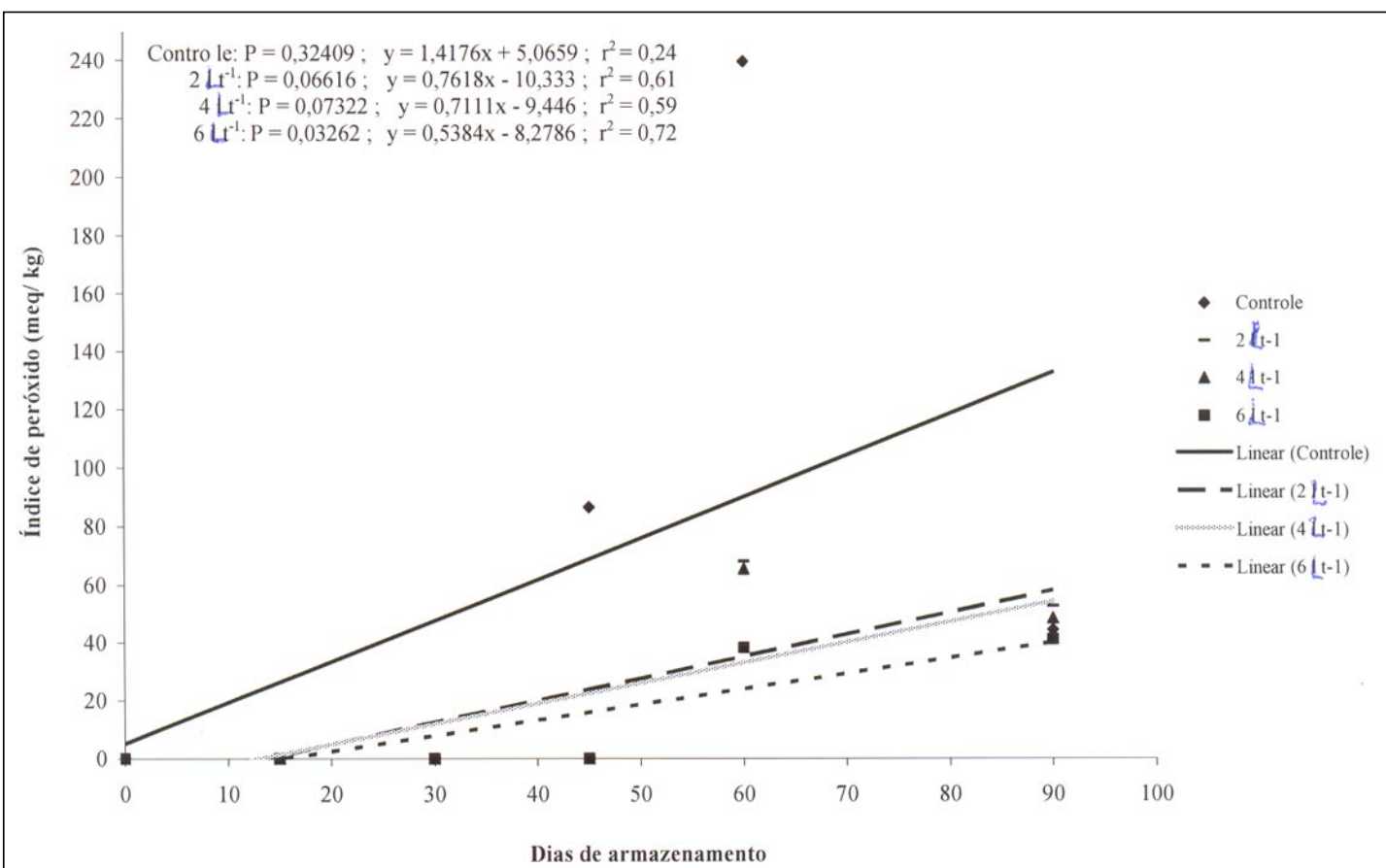

Figura 4 - Análise de regressão do parâmetro índice de peróxido em grão de soja desativado, tratado com mistura de ácidos orgânicos e seus sais, durante 90 dias de avaliação.

Ciência Rural, v.38, n.6, set, 2008. 
foram observados influência no período de armazenagem dos grãos dentro dos respectivos tratamentos. Não houve interação entre dosagens e períodos de avaliação para todas as variáveis analisadas.

\section{CONCLUSÕES}

A dosagem de seis litros de mistura de ácidos orgânicos e seus sais por tonelada de grão de soja desativado é eficiente no controle da contaminação e desenvolvimento fúngico, mesmo em condições favoráveis de umidade e atividade de água para o crescimento de fungos e leveduras.

\section{REFERÊNCIAS}

ALBUQUERQUE, R. et al. Tratamento de rações de aves com ácidos orgânicos: estudo da atividade bacteriana e avaliação de técnicas de recuperação de Salmonella spp. Brazilian Journal of Veterinary Research and Animal Science, v.35, n.3, p.279-282, 1998

ANFAL. Compêndio de alimentação animal. 4.ed. Brasília: ANFAL, 1998. 258p.

AOAC. Official Methods of Analysis of AOAC International. 16.ed. Arlington: AOAC International, 1995. 1456p.

BLIGH, E.G.; DYER, W.J. A rapid method for total lipid extraction and purification. Canadian Journal of Biochemistry and Physiology, v.37, n.10, p.911-917, 1959.

CASINI, C. Guía de almacenamiento de granos secos en bolsas plásticas. Manfredi: INTA, 2003. V.1, n.4, 17p.

DECKER, E.A. et al. Measuring antioxidant effectiveness in food. Journal of Agricultural and Food Chemistry, v.53, n.12, p.4303-4310, 2005.

DIEKMAN, M.A.; GREEN. M.L. Mycotoxins and reproduction in domestic livestock. Journal of Animal Science, v.70, n.6, p.1615-1627, 1992.

DITCHFIELD, C. Estudo dos métodos para a medida de atividade de água. 2000. 174f. Dissertação (Mestrado em Engenharia Química) - Universidade de São Paulo.

GOCK, M.A. et al. Influence of temperature, water activity and $\mathrm{pH}$ on growth of some xerophilic fungi. International Journal of Food Microbiology, v.81, n.1, p.11-19, 2003.

GOULD, G.W. Methods for preservation and extension of shelf life. International Journal of Food Microbiology, v.33, n.1, p.51-64, 1996.
GUYNOT, M.E. et al. Study of benzoate, propionate, and sorbate salts as mould spoilage inhibitors on intermediate moisture bakery products of low $\mathrm{pH}$ (4.5-5.5). International Journal of Food Microbiology, v.101, n.2, p.161-168, 2005.

HERMANNS, G. et al. Fungos e fumonisinas no período précolheita do milho. Ciência e Tecnologia dos Alimentos, v.26, n.1, p.7-10, 2006.

HOELTZ, M. Estudo da influência de manejos póscolheita na incidência de fungos e micotoxinas no arroz (Oryza sativa L.). 2005. 80f. Dissertação (Mestrado em Microbiologia de Alimentos) - Universidade Federal do Rio Grande do Sul.

LIN, C.D.; CHEN, T.C. Relative antifungal efficacies of phosphoric acid and other compounds on fungi isolated from poultry feed. Animal Feed Science and Technology, v.54, n.3, p.217-226, 1995

NAZER, A.I. et al. Combinations of food antimicrobials at low levels to inhibit the growth of Salmonella sv. Typhimurium: a synergistic effect? Food Microbiology, v.22, n.4, p.391-398, 2005.

PEIXOTO, R.R.; MAIER, J.C. Nutrição e alimentação animal. Pelotas: EDUCAT, 1993. 169p.

PONT, G. et al. El problema de la contaminación fúngica en la industria de piensos. Barcelona: Lucta, 2001. 119p.

RAHNEMA, S.; NEAL, S.M. Laboratory and field evaluation of commercial feed preservatives in the diet of nursery pigs. Journal of Animal Science, v.72, n.4, p.572-576, 1994.

SANTIN, J.A. Fungos de pré e pós-colheita e a qualidade de grãos de milho. 2001. 200f. Tese (Doutorado em Fitotecnia) - Universidade Federal do Rio Grande do Sul.

SAS INSTITUTE INC. SAS for Windows 98. NCSU, North Carolina, 1999.

SAVARD, T. et al. Characterization of spoilage yeasts isolated from fermented vegetables and inhibition by lactic, acetic and propionic acids. Food Microbiology, v.19, n.3, p.363-373, 2002.

SUHR, K.I.; NIELSEN, P.V. Effect of weak acid preservatives on growth of bakery product spoilage fungi at different water activities and $\mathrm{pH}$ values. International Journal of Food Microbiology, v.95, n.1, p.67-78, 2004.

TANIWAKI, M.H. Meios de cultura para contagem de fungos em alimentos. Sociedade Brasileira de Ciência e Tecnologia de Alimentos, v.30, n.2, p.132-141, 1996.

TEIXEIRA, J.C.; TEIXEIRA, L.F.A.C. Alimentação de bovinos leiteiros. Lavras: UFLA, 2001. 105p. 